Self-harm in Primary and Secondary Care. Clinical Guideline 16. Department of Health, 2004.

6 Saunders K, Hawton K, Fortune S, Farrell S. Attitudes and knowledge of clinical staff regarding people who self-harm: a systematic review. J Affect Disord 2012; 139: 205-16.

7 Chapman R, Martin C. Perceptions of Australian emergency staff towards patients presenting with deliberate self-poisoning: a qualitative perspective. Int Emerg Nurs 2014; 22: 140-5.

8 Heaton J. Reworking Qualitative Data. Sage, 2004.

9 Smith E. Using Secondary Data in Educational and Social Research. Open University Press, 2006.

10 Owens C, Sharkey S, Smithson J, Hewis E, Emmens T, Ford T, et al Building an online community to promote communication and collaborative learning between health professionals and young people who self-harm: an exploratory study. Health Expect 2015; 18: 81-94.

11 Smithson J, Sharkey S, Hewis E, Jones R, Emmens T, Ford T, et al. Problem presentation and responses on an online forum for young people who self-harm. Discourse Stud 2011; 13: 487-501.

12 Smithson J, Sharkey S, Hewis E, Jones R, Emmens T, Ford T, et al. Membership and boundary maintenance on an online self-harm forum. Qual Health Res 2011; 21: 1567-75.

13 Sharkey S, Jones R, Smithson J, Hewis E, Emmens T, Ford T, et al. Ethical practice in Internet research involving vulnerable people: lessons from a self-harm discussion forum study (SharpTalk). J Med Ethics 2011; 37 $752-8$.
14 Sharkey S, Smithson J, Hewis E, Jones R, Ford T, Owens C. Supportive interchanges and face-work as 'protective talk' in an online self-harm support forum. Commun Med 2012; 9: 71-82.

15 Braun V, Clarke V. Using thematic analysis in psychology. Qual Res Psychol 2006; 3: 77-101.

16 Jeffery R. Normal rubbish: deviant patients in casualty departments. Sociol Health IIIn 1979; 1: 90-107.

17 Hunter C, Chantler K, Kapur N, Cooper J. Service user perspectives on psychosocial assessment following self-harm and its impact on further help-seeking: a qualitative study. J Affect Disord 2013; 145: 315-23.

18 Tzeng W-C, Yang C-I, Tzeng N-S, Ma H-S, Chen L. The inner door: toward an understanding of suicidal patients. J Clin Nursing 2010; 19: 1396-404.

19 Ballatt J, Campling P. Intelligent Kindness: Reforming the Culture of Healthcare. RCPsych Publications, 2011.

20 Redelmeier D, Molin J, Tibshirani R. A randomised trial of compassionate care for the homeless in an emergency department. Lancet 1995; 345: 1131-4.

21 Owens C. Interventions for self-harm: are we measuring outcomes in the most appropriate way? Br J Psychiatry 2010; 197: 502-3.

22 Tudor Hart J, Dieppe P. Caring effects. Lancet 1996; 347: 1606-8.

23 Filip C. The importance of remaining empathic. Mcgill J Med 2009; 12: 134-6.

24 Breen B, McCann M. Healthcare providers attitudes and perceptions of 'inappropriate attendance' in the Emergency Department. Int Emerg Nurs 2013; 21: 180-5.

25 Steel J. Inappropriate - the patient or the service? Accid Emerg Nurs 1995; 3: $146-9$. psychiatry in history

\section{An 18th-century view of demonomania. 2: Vampirism - introduction}

\section{Fiona Subotsky}

Martinus Martini's 1782 dissertation on demonomania includes a considerable section on vampirism, on which topic more of his own original thought is evident, although the stories themselves are the usual ones found in other sources. For vampirism as a variety of insanity Martini is somewhat muddled as to whom should be diagnosed - the alleged vampire, the victims or the believers. I present here some of his observations in my own translation of the Latin. He begins:

I shall describe how to understand the madness of those who persuade themselves that the ghosts of dead men or the recently dead themselves go out at night from the tomb and leap on the sleeping, whom they drag to death by draining their blood.

As for the name, he notes that:

There is a certain species of bat in Brazil which at night opens the veins of sleeping men and animals, and sucks the blood. It is called the Vampire Bat by Linnaeus... This name seems to take its origin from the Slavonic language, from the word 'ulpir', or 'vampir', which signifies bloodsucker.

Martini recounts several vampire stories, which he acknowledges are largely taken from Augustin Calmet, a French Benedictine prior and theologian, whose Treaty on the Apparitions of Spirits and Vampires, or ghosts of Hungary, Moravia, \& c., was published in 1751 and is still used as a major reference for vampire lore.

'Vampirism - Stories' and 'Vampirism - Explanation' will be published in subsequent issues of the BJPsych. 